\title{
COMO OS CONTOS DE FADAS E OS COMENTÁRIOS NA INTERNET REFLETEM A SOCIEDADE: CHAPEUZINHO VERMELHO E A CULTURA DO ESTUPRO
}

\author{
Thais Ferreira Dos Santos ${ }^{1}$, Leandro Antônio Guirro². \\ 'Universidade do Oeste Paulista - UNOESTE, Especialização em Literatura e Jornalismo, Presidente \\ Prudente, SP. ${ }^{2}$ Universidade Estadual Paulista - UNESP, Assis, SP. E-mail: \\ thais ferreirasantos@outlook.com.
}

\section{RESUMO}

Este trabalho tem como objetivo analisar os comentários da notícia do caso de estupro coletivo ocorrido no Rio de Janeiro, que responsabilizam a vítima pelo crime. Os comentários escolhidos para a análise foram realizados na página do Fantástico após a veiculação da reportagem elaborada pelo programa de televisão da Rede Globo. A análise faz um paralelo com o conto Chapeuzinho Vermelho. Para realizar essa pesquisa emprega-se o método dialético de Hegel segundo as definições de Diehl e Tatim, no qual os fatos são tomados dentro de um contexto, aliado a técnica de análise de conteúdo desenvolvida por Laurence Bardin citada por Fonseca Júnior.

Palavras-chave: Comentários, Estupro Coletivo, Contos de Fadas.

\section{HOW DO FAIRY TALES AND ONLINE COMMENTS REFLECT OUR SOCIETY: LITTLE RED RIDING HOOD AND THE RAPE CULTURE}

\begin{abstract}
This scholarly work aims to analyze the comments of the news of a gang rape in Rio de Janeiro, which blamed the victim for the crime. The commentaries chosen for analysis were performed at Fantástico website right after the news be shown by a television program on the Rede Globo. The analysis of those online comments does a parallel with the tale of Little Red Riding Hood. To accomplish this research, the work employs the dialectical method of Hegel according to the definitions of Diehl and Tatim, in which the facts are taken inside a context, allied with the method of content analysis developed by Laurence Bardin quoted by Fonseca Junior.
\end{abstract}

Keywords: Comments, Gang Rape, Fairy Tales. 


\section{INTRODUÇÃO}

O intuito desse artigo é fazer um paralelo do conto Chapeuzinho Vermelho com o caso de estupro coletivo de uma garota de 16 anos, ocorrido no Rio de Janeiro. Com base nos comentários postados na página do Fantástico da Rede Globo, pretende-se verificar como a cultura do estupro influi no ato de culpar a vítima, assim como os contos de fadas, que ao longo do tempo sofreram alterações no enredo, partindo da narrativa oral em contraponto a versão de Charles Perrault.

Os comentários na página do Fantástico referentes a menor de idade, vítima de estupro, foram postados após o programa veicular a matéria que apresenta detalhes da investigação policial com a cronologia dos fatos. O objetivo é relacionar as declarações ao comportamento relativo a cultura do estupro.

Assim pretende-se entender as intertextualidades contidas em duas versões do conto Chapeuzinho Vermelho, focado na construção de uma moral supostamente contida na história, que culpa a personagem principal pelo desfecho da narrativa.

\section{METODOLOGIA}

Para realizar este trabalho, utilizaram-se métodos e técnicas de pesquisa científica. De acordo com Cervo, Bervian e Silva (2007, p.29), para delimitar um método é imprescindível conhecer o objetivo da pesquisa. Para concretizar e comprovar as hipóteses levantadas são empregadas as técnicas.

Por método, entende-se o dispositivo ordenado, o procedimento sistemático, em plano geral. A técnica por sua vez, é a aplicação do plano metodológico e a forma especial de o executar. Comparando pode-se dizer que a relação existente entre método e técnica é a mesma que existe entre estratégia e tática. A técnica está subordinada ao método, sendo sua auxiliar imprescindível. (CERVO; BERVIAN; SILVA, p.29)

O presente estudo vale-se do método dialético, fundamentado na dialética de Hegel, comumente empregado em pesquisa qualitativa. "É um método de interpretação dinâmica e totalizante da realidade, segundo o qual os fatos não podem ser tomados fora de um contexto social, político, econômico". (DIEHL; TATIM, 2004, p.50)

Para auxiliar o método e proporcionar maior clareza e objetividade à proposta analítica, opta-se como técnica a análise de conteúdo que permite aplicar a todo conteúdo uma análise semiológica ou de discurso. De acordo com a pesquisadora Laurence Bardin, uma das responsáveis pelo desenvolvimento da técnica de análise de conteúdo, é possível estruturá-la em cinco etapas: "organização da análise, a codificação, a categorização, a interferência e o tratamento informático" (BARDIN, 1988, apud. FONSECA JÚNIOR, 2005)

Esta pesquisa propõe realizar uma análise dos comentários feitos na página do Fantástico, referentes ao caso de estupro coletivo, ocorrido no Rio de Janeiro. Além de fazer um paralelo com o conto Chapeuzinho Vermelho, apoiando-se no Minimanual do jornalismo humanizado - Part. I: Violência contra a mulher, elaborado pela ONG Think Olga.

\section{RESULTADOS}

De acordo com dados divulgados pelo G1, portal de notícias da Rede Globo, o estupro teria ocorrido na manhã de sábado, 21 de maio, e na noite de domingo, 22 de maio:

[...] a adolescente saiu de um baile funk com Raí, o jogador de futebol Lucas Perdomo, de 20 anos, e mais uma garota às $7 \mathrm{~h}$ da manhã de sábado, 21 de maio. Na festa, eles teriam feito uso de bebidas alcoólicas, maconha e 
cheirinho da loló (entorpecente feito com clorofórmio e éter). Os quatro foram a uma casa abandonada da comunidade do Morro do Barão. Às 10h do mesmo dia, Raí, Lucas e a outra menina decidiram sair do local, deixando para trás a menor, que ainda está sob o efeito de drogas. Às 11h, a menina teria sido encontrada desacordada pelo traficante Moisés Camilo de Lucena, conhecido como Canário, de 28 anos. O homem pegou a jovem e a levou para outra casa. Ele teria sido o primeiro a estuprá-la. As investigações apontam que a adolescente foi estuprada, no mínimo, duas vezes: no sábado pela manhã e no domingo, à noite. Os policiais acreditam que o número de envolvidos no crime possa ser maior. Quando a jovem foi violentada na noite de domingo, Raí chegou em uma casa da comunidade acompanhado de Raphael Duarte Belo, de 41 anos, e de um homem identificado como Jefinho. Neste segundo momento, eles abusaram da adolescente, gravaram vídeos e tiraram fotos. (G1.globo.com, 2016)

Na edição do dia 05 de junho de 2016, o Fantástico da Rede Globo, leva ao ar uma matéria sobre o caso. O no site do programa, o VT (vídeo tape), postado no mesmo dia, às $23 \mathrm{~h}$, recebe o título "Vídeo de celular mostra que jovem de 16 anos foi abusada e tentou reagir", e a linha fina: "Garota foi estuprada na zona oeste do Rio de Janeiro. Na última sexta-feira, policiais acharam um celular, outra prova que não deixa dúvidas sobre crime". (G1.globo.com, 2016)

De acordo com o Minimanual elaborado pela ONG Think Olga os títulos e conteúdos jornalismo influenciam diretamente na compreensão e julgamento do público perante o fato. "Estupro não é sexo. Sexo é consensual. "Suavizar" este fato, substituindo estupro por "obrigou a fazer sexo" [...] é diminuir a gravidade do crime. Não é sexo para a vítima". (THINK OLGA, p.10, 2016)

A partir desse posicionamento pode-se afirmar que o título e a linha fina, empregados pelo Fantástico, não influenciaram os internautas. Os comentários, referentes ao caso, foram postados no mesmo período, não é possível determinar com exatidão o dia ou o horário, pois o sistema da página padrão da Rede Globo na internet exibe apenas uma amostragem. O primeiro comentário (FIGURA 1), realizado pela internauta identificada por Nathalia Frazão, é datado em "1 mês atrás", decorrido a data em que a imagem fora salva, no caso, em 20 de julho de 2016.

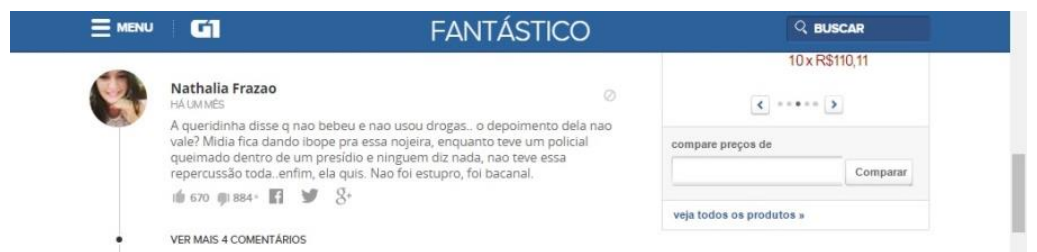

Figura 01.Comentário I

Fonte: G1.globo.com, 2016

A internauta escreveu: "A queridinha disse que não bebeu e não usou drogas. $O$ depoimento dela vale? Mídia fica dando ibope pra essa nojeira [...] enfim ela quis. Não foi estupro, foi bacanal". Em resposta outros internautas repreenderam o posicionamento da internauta, porém mesmo assim seguiram outros comentários semelhantes. 

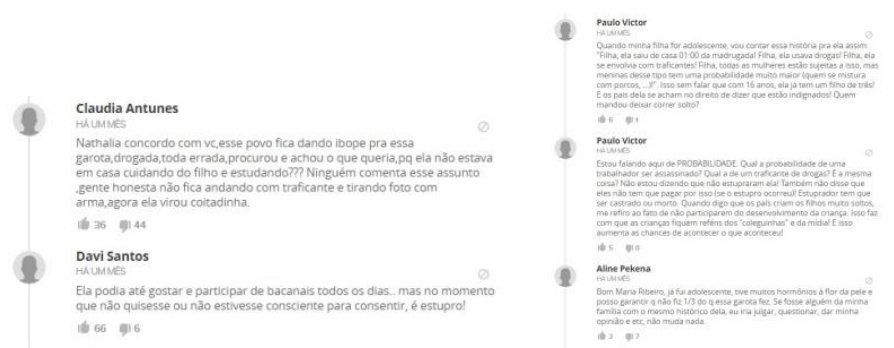

Figura 02. Comentários II e III

Fonte: G1.globo.com, 2016

A internauta Claudia Antunes (FIGURA 2) atribui o ocorrido à vítima ao dizer: "Por que ela não estava em casa cuidando do filho ou estudando?". Já Paulo Victor, autor de dois comentários atribui o crime ao comportamento da vítima. Ele afirma: "Todas as mulheres estão sujeitas a isso, mas meninas desse tipo tem uma probabilidade muito maior [...]. Isso sem falar que com 16 anos, ela já tem um filho de três!". Os comentários seguintes seguem o mesmo padrão.

O site funciona como uma rede que conecta os indivíduos por meio dos perfis, a propagação de opiniões desencadeia uma discussão. "Ao estudar-se a difusão de informações, busca-se compreender como a informação é difundida entre diferentes atores sociais, ou seja, como a informação passa de um indivíduo para outro". (GRUHL et al., 2004 apud. RECUERO; ZAGO, 2009, p. 71)

O programa de televisão "Fantástico", no ar, interruptamente, há mais de 40 anos, exerce grande influência sobre a sociedade, "se tornou um dos produtos mais familiares do grande público" (ROCHA; AUCAR apud REIS, 2013, p.7)

"A primeira exibição da revista eletrônica de variedades, Fantástico: o show da vida, pela Rede Globo, ocorreu em 5 de agosto de 1973." (REIS, 2013, p.7). O programa, criado pelo então diretor de Operações da emissora, José Bonifácio de Oliveira Sobrinho, o Boni, nasceu com a proposta visual inspirada nas revistas sofisticadas, voltado à exploração da realidade, representada pelo jornalismo, sem abrir mão da ficção, concebida pela dramaturgia.

\section{DISCUSSÃO}

A partir da versão, citada por Darnton, do conto Chapeuzinho Vermelho faz-se uma relação com as alterações sofridas ao longo do tempo e a intenção de tais histórias na cultura dos camponeses, com os comentários postados na página do Fantástico sobre o caso de estupro coletivo.

De acordo com Darnton (1986, p.21), o texto assemelha-se ao conto, "mais ou menos como era narrado em torno às lareiras, nas cabanas dos camponeses, durante as longas noites de inverno, na França do século XVIII".

Certo dia, a mãe de uma menina mandou que ela levasse um pouco de pão e de leite para sua avó. Quando a menina ia caminhando pela floresta, um lobo aproximou-se e perguntou-lhe para onde se dirigia. _Para a casa de vovó - ela respondeu. _Por que caminho você vai, o dos alfinetes ou o das agulhas? _ O das agulhas. Então o lobo seguiu pelo caminho dos alfinetes e chegou primeiro à casa. Matou a avó, despejou seu sangue numa garrafa e cortou sua carne em fatias, colocando tudo numa travessa. Depois, vestiu sua roupa de dormir e ficou deitado na cama, à espera. Pam, pam. Entre, querida. _ Olá, vovó. Trouxe para a senhora um pouco de pão e de leite. _Sirva-se também de alguma coisa, minha querida. Há carne e vinho na copa. A menina comeu o que the era oferecido e, enquanto o fazia um gatinho disse: "menina perdida! Comer a carne e beber o sangue de sua avó!". Então, o lobo disse:_Tire a roupa e deite-se na cama comigo._Onde 
ponho meu avental? _Jogue no fogo. Você não vai amis precisar dele. Para cada peça de roupa - corpete, saia, anágua e meias - a menina fazia a mesma pergunta. E, a cada vez, o lobo respondia: _Jogue no fogo. Você não vai mais precisar dela. Quando a menina se deitou na cama, disse:_Ah, vovó! Como você é peluda!_É para manter você mais aquecida, querida. _Ah, vovó! Que ombros largos você tem!_É para carregar melhor a lenha, querida. _Ah vovó! Como são compridas as suas unhas! _É para me coçar melhor, querida._Ah, vovó! Que dentes grandes você tem! É para melhor comer você, querida. E ele a devorou. (DARNTON, 1986, p.21-22)

Existem inúmeras versões para o conto, algumas trazem explícita a moral da história, outras, como a citada, deixam implícita a significação dos acontecimentos. "Qual é a moral dessa história? Para as meninas, é clara: afastem-se dos lobos. Para os historiadores, parece dizer algo sobre o universo mental dos camponeses no início dos Tempos Modernos". (DARNTON, 1986, p.22)

O escritor francês Charles Perrault publica o conto, pela primeira vez, em 1697, com o nome "Le Petit Chaperon Rouge". "O texto de Perrault tem um caráter de fábula moral, ensina que quem transgride as regras se expõe ao perigo, é punido e fim de história". (LICHTENSTEIN; CORSO, 2006, p.59)

Algumas versões Perrault são acompanhadas de um versinho, primeiros registros de uma 'moral da história' explícita:

Vemos aqui que as meninas e, sobretudo, as mocinhas lindas, elegantes e finas, não devem a qualquer um escutar. E se fazem-no, não é surpresa, que do lobo virem o jantar. Falo "do" lobo, pois nem todos eles são de fato equiparáveis. Alguns são até muito amáveis, serenos, sem fel nem irritação. Esses doces lobos, com toda a educação, acompanham as jovens senhoritas pelos becos afora e além do portão. Mas ai! Esses lobos gentis e prestimosos são, entre todos, os mais perigosos. (PERRAULT apud LICHTENSTEIN; CORSO, 2006, p.59-60)

Chapeuzinho Vermelho de Charles Perrault foi publicada para a corte do rei Louis XIV. Na época "não se tinha a preocupação de se distinguir socialmente uma criança de um adulto". (CORDEIRO; SANTOS, 2012, p.6). Não havia o entendimento que há hoje, a vítima menor de 14 anos não possui discernimento para consentir, o estupro de vulnerável é crime e previsto em lei.

\section{CONCLUSÃO}

As primeiras versões do conto supõem uma leitura de teor sexual da relação entre Chapeuzinho Vermelho e o Lobo, logo, cria-se uma resposta dos ouvintes (tradição oral) e dos leitores, a chamada 'moral da história' não se alterou com as mudanças no enredo. Tanto a Chapeuzinho Vermelho do século XVIII, quanto a Chapeuzinho do Século XXI, salva da barriga do lobo pelo caçador, ambas são responsabilizadas pelo assédio ou desfecho.

A Culpabilização da Vítima, defendida em 1976 por William Ryan, é caracterizada pela maior atribuição de um crime à vítima do que ao criminoso.

O estupro é um dos crimes mais subnotificados, por várias razões. A primeira delas é que, em uma sociedade patriarcal e machista como a brasileira, ao revelar que sofreram essa violência, as mulheres, maioria entre as vítimas de estupro no país ( $89 \%$, segundo o Ipea), têm grandes 
chances de ser culpabilizadas pelo fato - sendo que o único responsável pelo crime é o estuprador. (THINK OLGA, 2016, p.6)

O patriarcado confere um grau de influência nas escolhas e julgamentos em um caso referente a uma mulher, o que desencadeia a cultura do estupro, na qual é imposto a mulher a obrigatoriedade de servir sexualmente ao homem.

Os homens são definidos em termos de sua conquista nas instituições sociais elaboradas, eles são participantes, por excelência, nos sistemas das experiências humanas feitos pelos homens. Num nível moral, o mundo da "cultura" é deles. As mulheres, por outro lado, dirigem as vidas, que parecem ser irrelevantes, à distinção formal da ordem social. Seu status é derivado de seu estágio no ciclo da vida, de suas funções biológicas e, em particular, de seus laços sexuais e biológicos a homens específicos. (ROSALDO apud CUNHA FILHO; FERNANDES, 1979)

Se os contos refletiam a cultura dos camponeses, as redes sociais e os comentários em páginas da internet, refletem a cultura contemporânea que ainda é moldada na cultura do patriarcado e mesmo a linguagem jornalística respeitosamente não atribuir a culpa neste caso à vítima a influência cultural foi mais forte.

\section{REFERÊNCIAS}

CERVO, Amado L.; BERVIAN, Pedro A.; SILVA, Roberto da. Metodologia Científica. 6. ed. São Paulo: Pearson Prentice Hall, 2007.

CORDEIRO, L. P.; SANTOS, A. S. Chapeuzinho Vermelho: comparação de versões traduzidas no Brasil. In: Encontro Nacional de Literatura Infanto-Juvenil e Ensino - Enlije, 4., Universidade Federal de Campina Grande (UFCG), vol.1, num. 1. Anais... Campina Grande: UFCG, 2012. Disponível em:

<http://editorarealize.com.br/revistas/enlije/trabalhos/44a8b5d0c833b23af59f147546dbe62e_56 _105_.pdf>. Acesso em: 08 de ago. 2016.

CUNHA FILHO. Francisco Humberto; FERNANDES, Leonísia Moura. Violência sexual e culpabilização da vítima: sociedade patriarcal e seus reflexos no Ordenamento jurídico brasileiro. In: Direitos, gênero e movimentos sociais II. Organização CONPEDI/UFPB; coordenadores: Juliana Teixeira Esteves, José Luciano Albino Barbosa, Pablo Ricardo de Lima Falcão. - Florianópolis: CONPEDI, 2014.

DARNTON, Robert. 0 grande massacre de gatos, e outros episódios da história cultural francesa. Tradução: Sonia Coutinho. Rio de Janeiro: Graal, 1986.

DIEHL, Astor Antônio. Tatim, Denise Carvalho. Pesquisa em ciências sociais aplicadas: métodos e técnicas. São Paulo: Prentice Hall, 2004.

G1, Rio de Janeiro. Polícia conclui inquérito de estupro coletivo no Rio com sete indiciados. Disponível em: <http://g1.globo.com/rio-de-janeiro/noticia/2016/06/policia-conclui-inquerito-deestupro-coletivo-no-rio-com-sete-indiciados.html>. Acesso em: 03 de ago. 2016.

LICHTENSTEIN, Diana; CORSO, Mário. Fadas no Divã: Psicanálise nas Histórias Infantis. Porto Alegre: Artmed, 2006. 
RECUERO, R; ZAGO, Gabriela. "RT, por favor": considerações sobre a difusão de informações no Twitter. Revista Fronteiras - estudos midiáticos 12(2): 69-81, maio/agosto 2010. Disponível em: <revistas.unisinos.br/index.php/fronteiras/article/view/4668/1891>. Acesso em: 04 de ago. 2016.

REIS, Leidiane Vieira dos. O Fantástico a partir da narrativa tecida sobre o incêndio na boate Kiss: entre jornalismo e ficção. Universidade Federal de Juiz de Fora: Minas Gerais, 2013. Disponível em: <http://www.ufrgs.br/alcar/encontros-nacionais-1/9o-encontro-2013/artigos/gt-historia-dojornalismo/o-fantastico-a-partir-da-narrativa-tecida-sobre-o-incendio-na-boate-kiss-entrejornalismo-e-ficcao>. Acesso em: 12 de ago. 2016.

THINK OLGA, Ong. Minimanual do Jornalismo Humanizado Parte I: Violência contra a mulher. Disponível em: <http://thinkolga.com/olga/wp-content/uploads/2016/06/minimanual_V2.pdf>. Acesso em: 08 de ago. 2016. 